\title{
Capital espiritual e as relações econômicas: Empreendedorismo em organizações religiosas
}

\section{Spiritual capital and economic relations: Entrepreneurship in religious organizations}

\author{
Mauricio C. Serafim ${ }^{1}$ \\ Carolina Andion ${ }^{2}$
}

\begin{abstract}
Resumo
Este artigo busca evidenciar como as organizações religiosas podem ser geradoras de capital social, na medida em que estabelecem relações sociais que beneficiam a ação de seus membros-empreendedores. Neste sentido, a participação nesses espaços pode ser interpretada como uma nova fonte de capital social ou, mais especificamente, de capital espiritual. A hipótese central é de que importantes recursos geradores de capital social (COLEMAN, 1988) - tais como obrigações e expectativas, canais de informação, normas ou sanções, fortalecimento de laços sociais e organização social - podem ser acionados pela prática religiosa. Para explorar essa hipótese, a estratégia de pesquisa adotada foi o estudo de caso qualitativo e comparativo de duas organizações religiosas brasileiras: uma evangélica (Igreja Renascer em Cristo) e outra católica (Movimento dos Focolares). Os dados foram coletados por meio de observação, entrevistas e pesquisa documental. Constatamos que, de modo geral, as estruturas religiosas das organizações investigadas formam um tipo especial de capital social, denominado capital espiritual (porque de origem religiosa) - por meio de "fechamento" de redes sociais, organização social apropriada, obrigações e normas, canais de informações, estruturas de plausibilidade e redes religiosas de ajuda mútua. Evidenciamos características específicas do capital espiritual que não são suficientemente abordadas pelas teorias do capital social, como a formulada por Coleman. Por fim, identificamos diferenças e semelhanças de formação de capital espiritual nas organizações religiosas investigadas, tendo como foco o comportamento do empreendedor-membro.
\end{abstract}

Palavras-chave: Capital social; capital espiritual; organizações religiosas; dádiva; empreendedorismo.

\begin{abstract}
This article aims to show how religious organizations can generate social capital, to the extent of establishing social relations that improve the action of its members-entrepreneurs. In this sense, participation in these spaces can be interpreted as a new source of capital or, more specifically, spiritual capital. The central hypothesis is that significant resource generators of social capital (COLEMAN, 1988) such as obligations and expectations, information channels, norms and sanctions, strengthening social ties and social organization can be triggered by religious practice. To explore this hypothesis, the research strategy adopted was the qualitative comparative case study of two religious organizations in Brazil. The first is the Catholic Church, called the Focolare Movement, and the other one is an Evangelical Church, locally denominated "Renascer em Cristo" (Reborn in Christ). The data were collected through observation, interviews and documentary research. It was found that, in general, the religious structures of the firms form a special type of social capital, denominated spiritual capital (due to its religious origin) - through the closure of social networks, appropriable social organization, obligations and norms, information channels (COLEMAN, 1988), structures of plausibility and religious networks of mutual aid. The results revealed specific features of spiritual capital which are not sufficiently addressed by theories of social capital, as formulated by Coleman. Finally, we identified differences and similarities in the formation of the spiritual capital of the religious organizations under study, focusing on the behavior of the members-entrepreneurs.
\end{abstract}

Key words: Social capital; spiritual capital; religious organizations; gift; entrepreneurship.

\footnotetext{
Artigo submetido em novembro de 2009 e aceito para publicação em agosto de 2010.

1 Doutor em Administração de Empresas pela Escola de Administração de Empresas da Fundação Getulio Vargas de São Paulo FGV-EAESP; Departamento de Administração Pública e Mestrado Profissional em Administração, Centro de Ciências da Administração e Socioeconômicas, Universidade do Estado de Santa Catarina (ESAG/UDESC). Endereço: Av. Madre Benvenuta, 2037, Itacorubi, Florianópolis - SC, 88035-001; Email: serafim.esag@gmail.com.

${ }^{2}$ Doutora em Ciências Humanas pela Universidade Federal de Santa Catarina (UFSC); Professora do Mestrado Profissional em Administração e Diretora de Extensão do Centro de Ciências da Administração e Socioeconômicas (ESAG) da Universidade Estadual de Santa Catarina (UDESC) e Pesquisadora do Centro de Pesquisa e Informação em Economia Pública, Social e Cooperativa (CIRIEC-Brasil). Endereço Institucional: ESAG/UDESC Avenida Madre Benvenura, 2037, Florianópolis, Santa Catarina, CEP 88.035-001, E-mail: carol.andion@terra.com.br.
} 


\section{Introdução}

Digo-vos ainda isto: se dois de vós se unirdes sobre a terra para pedir, seja o que for, consegui-lo-ão de meu Pai que está nos céus. Porque onde dois ou três estão reunidos em meu nome, aí estou eu no meio deles (Evangelho segundo São Mateus 18, 19-20).

Capital social (KS) é, simultaneamente, um dos conceitos mais promissores e criticados que surgiram no último quartel de século. É utilizado por autores que desejam incorporar fatores sociais na análise de fenômenos econômicos (CHANG, 2006) e explicar ampla variedade de comportamentos individuais e coletivos, tais como a obtenção de status e mobilidade social, vantagens competitivas em organizações econômicas, participação política, e bem-estar físico e psicológico (LIN, 2006).

Para o estudo do empreendedorismo, em particular, a importância do conceito de KS está na hipótese de que KS impacta positivamente nos empreendimentos e proporciona maior probabilidade de sobrevivência (FUKUYAMA, 2001). Elevados níveis de KS propiciam aos empreendedores não apenas uma maior facilidade de acesso e compartilhamento de informações privilegiadas, mas também conhecimento acerca de oportunidades de negócios. Adicionalmente, possibilitam a aquisição antecipada de recursos e facilitam a reunião de esforços para o desenvolvimento de oportunidades comerciais (MARTES; RODRIGUEZ, 2005). Além disso, os indivíduos e as organizações se beneficiam do alto grau de confiança entre os membros de sua rede, obtendo vantagens como menor ocorrência de comportamentos oportunistas, redução dos custos de transação necessários à realização de negócios e acesso a relações pessoais importantes para a abertura e manutenção do negócio (BARON; MARKMAM, 2003; NAHAPIET; GHOSHAL, 1998).

Entretanto, apesar de haver uma bibliografia considerável abordando a relação entre capital social e empreendedorismo, ainda é pouca explorada a relação entre o capital social e o fenômeno da expansão de organizações religiosas no Brasil, o que traz em seu bojo a hibridação de técnicas e modelos de gestão da administração tradicional com valores e crenças espirituais que orientam, em muitos casos, a prática de seus membros-empreendedores.

É nessa perspectiva que pretendemos discutir, a partir de uma pesquisa de campo, como as organizações religiosas podem estabelecer relações sociais que beneficiam a ação de seus membros-empreendedores, na medida em que esses agentes conseguem, a partir da sua participação nessas organizações, fazer parte de redes que facilitam o acesso a novos recursos e à sua mobilização. Nesse sentido, a participação nesses espaços pode ser interpretada como uma nova fonte de capital social. A hipótese central é de que importantes recursos geradores de capital social (COLEMAN, 1988), como obrigações e expectativas, canais de informação, normas ou sanções, fortalecimento de laços sociais e organização social podem ser acionados pela prática religiosa. Consideramos, então, que o capital social e a coesão dos laços sociais provenientes das organizações religiosas investigadas criam recursos organizacionais que são disponibilizados intencionalmente para que os empreendedores possam acessá-los (SERAFIM; MARTES, 2007).

A seguir, procuramos examinar essa hipótese, demonstrando comparativamente as estruturas sociais que facilitam o KS e as formas de KS provenientes dessas estruturas, tendo como principal referência o trabalho de Coleman (1988). Complementarmente, consideramos também a abordagem da dádiva (GODBOUT, 1998; MAUSS, 2003), para melhor compreender como são criados e mantidos os vínculos sociais, elementos primordiais na constituição do KS. Críticas ao trabalho de Coleman são oferecidas a partir da pesquisa de campo e da abordagem do sistema de dádiva.

\section{Capital social na abordagem de Coleman}

James S. Coleman, sociólogo americano da Universidade de Chicago, foi quem lançou e deu visibilidade ao conceito de KS no campo da sociologia americana, no estudo em que destaca a importância desse capital na aquisição de capital humano (COLEMAN, 1988). O autor parte do pressuposto da teoria da ação racional, segundo o qual se, cada ator tem controle sobre certos tipos de recursos e possui interesses em certos recursos e eventos, então o KS constitui um tipo particular de recurso disponível para esse ator. Assim, KS é definido pela 
sua função, tratando-se de "[...] uma variedade de entidades diferentes, com dois elementos em comum: constituem as estruturas sociais e facilitam certas ações dos atores - sejam pessoas ou atores corporativos - no interior da estrutura" (COLEMAN, 1988, p.S98). Em outras palavras, a importância do conceito está, antes de tudo, na sua capacidade de identificar certos aspectos da estrutura social pelas suas funções. ${ }^{1} \mathrm{KS}$ compreende uma dimensão da estrutura social, cuja função é servir de recurso para facilitar a ação de atores que desejam alcançar determinados objetivos (ibidem, p.S101).

Da mesma forma que outros tipos de capital, o KS é produtivo porque certos fins são alcançados, e isso não seria possível na sua falta. Coleman acrescenta que "como o capital físico e capital humano, o capital social não é completamente equivalente [válido em todas as situações], mas pode ser específico para certas atividades. Uma dada forma de KS, valiosa para facilitar certas ações, pode ser inútil ou mesmo prejudicial em outras" (ibidem). Por outro lado, tratando-se de recurso disponível nas estruturas sociais, ele facilita aos atores atingirem seus objetivos, independentemente dos valores que orientem esses objetivos, sejam tais valores moralmente bons ou maus.

Assim, "diferentemente de outras formas de capital, o KS é inerente às estruturas de relações entre os atores. Ele não está armazenado nos próprios atores ou nas ferramentas físicas de produção" (ibidem). Para Coleman, KS é uma característica das organizações sociais e está localizado em um grupo ou em uma organização. Apesar de poder servir como um recurso para atores coletivos, o KS é abordado pelo autor, principalmente, como um recurso para atores individuais.

Diferentemente de Bourdieu (1986) - que empregou o conceito para descrever como os grupos de elite, por meio de seus contatos, reproduzem seus privilégios - Coleman aborda os relacionamentos sociais de grupos que não pertencem à elite (BARON; FIELD; SCHÜLLER, 2000). Nessa perspectiva, é possível aproximar os argumentos de Coleman da teoria da ação racional (OLSON, 1999) e da perspectiva do individualismo metodológico. Coleman considera KS um recurso voltado principalmente para a ação, um caminho para que a estrutura social seja inserida no paradigma da ação racional. Nesse ponto, seu entendimento difere do defendido nas abordagens de Putnam (1993) e dos autores que tratam o fenômeno da dádiva (GODBOUT, 1998; MAUSS, 2003), para os quais o capital social está intrinsecamente ligado às relações sociais. Apesar de basearse em Coleman e citá-lo inúmeras vezes, Putnam (1993) enfatiza o aspecto relacional e simbólico do capital social, demonstrando que a presença de um forte capital social numa comunidade é caracterizada pela existência de laços de confiança, regras de reciprocidade e participação cívica. Para o autor, o capital social é gerado, principalmente, pela socialização, sendo, portanto, um fator de fortalecimento da democracia, o que reduziria a probabilidade de práticas de deserção, a acomodação e o oportunismo.

Porém, Coleman (1988) também considera KS uma ferramenta útil para o desenvolvimento de uma orientação sociológica que integra alguns componentes dessas duas linhas teóricas. ${ }^{2}$ A primeira linha citada, utilizada pela maioria dos economistas (especialmente, os neoclássicos), considera ator aquele que age de forma independente e autointeressada. Sua principal virtude é a de levar em conta um princípio de ação: a maximização da utilidade. Já a sua principal fraqueza estaria na pouca ênfase dada às considerações da realidade empírica, tais como: a de que a ação dos indivíduos é influenciada pelo contexto social e a de que as normas, a confiança interpessoal, as redes sociais e a organização social são importantes também no funcionamento da economia, entre outras. A segunda linha - mais condizente com a leitura feita por Putnan e utilizada por muitos sociólogos - considera o ator como socializado, enquanto a ação é tida como orientada por normas sociais, regras e obrigações. Sua principal virtude está na habilidade de descrever a ação num contexto social e explicar como essa ação é moldada, coagida e redirecionada pelo contexto social. Sua principal limitação está em desconsiderar qualquer fonte interna de ação que forneça ao ator um propósito ou direção. ${ }^{3}$ Nesse sentido, Greeley (1997) afirma que o conceito de Coleman é útil por destacar a importância de abordar os recursos socioestruturais e sua influência sobre o comportamento humano, compreendendo o comportamento dos agentes econômicos a partir de uma nova perspectiva, além da economia neoclássica.

Coleman (1988) faz ainda as seguintes diferenciações: o capital físico é criado por mudanças no desenvolvimento de ferramentas que facilitam a produção; o capital humano é criado por mudanças em pessoas que adquirem habilidades e capacidades que os tornam aptas a agir de novas maneiras. Segundo o autor, o KS 
se forma por meio de mudanças nas relações interpessoais, facilitando a ação. Coleman observa que o capital físico é totalmente tangível, sendo incorporado em formas materiais observáveis, enquanto o capital humano é menos tangível, sendo incorporado em habilidades e conhecimentos adquiridos por um indivíduo. O KS seria o menos tangível de todos, justamente por existir nas relações entre pessoas.

Um dos maiores méritos do trabalho de Coleman é que, ao utilizar o conceito de KS num trabalho empírico, desenvolveu um meio de operacionalizá-lo para a pesquisa. Ao explorar como os recursos do KS podem contrabalançar baixos níveis de capital humano e cultural, demonstrou os meios tangíveis pelos quais o KS surgiu para interagir com outros aspectos da estratificação. Além disso, desenvolveu ainda a ideia de KS como um bem público (BARON; FIELD; SCHÜLLER, 2000). ${ }^{4}$ Essas características foram, provavelmente, uma das razões de sua influência em muitos estudos, entre eles, os de Putnam (1993), ${ }^{5}$ como observado anteriormente.

Além do já exposto acerca do modelo de Coleman, é preciso detalhar os aspectos das estruturas sociais relacionados ao KS, o que segundo o autor envolve: (a) formas de capital social e (b) estruturas sociais que facilitam tais formas. As formas que constituem KS são os recursos que permitem aos atores acessá-lo, os quais, segundo Coleman, seriam três. O primeiro recurso, denominado pelo autor de obrigações e expectativas, estabelece os elementos de crédito, reciprocidade e confiança da seguinte forma: se $A$ faz algo para $B$ e confia que $B$ retribuirá no futuro, é estabelecida uma expectativa em $A$ e uma obrigação (obligation - dever, favor) da parte de $B$. Essa obrigação pode ser entendida como um crédito obtido por $A$ por ter feito algo a $B$. A analogia com o capital financeiro é válida se $A$ obtém um grande número desses créditos de pessoas com as quais tem relações. Essa forma de KS depende de dois elementos: de confiabilidade (ou lealdade - trustworthiness) do ambiente social - de modo que as obrigações sejam retribuídas - e da amplitude efetiva dessas obrigações. Os indivíduos que estão em estruturas sociais com alto nível de obrigações possuem mais KS.

Quanto ao segundo recurso, canais de informação, o autor afirma que a potencialidade para informações, inerente às estruturas sociais, é uma importante forma de KS. A informação tem como função facilitar a ação, embora haja custos. ${ }^{6}$ Um modo de obtê-la é recorrer às relações sociais mantidas para outros propósitos, a exemplo da utilização da rede de amigos como fonte de informação para a compra de um carro usado, cujo mercado é desconhecido pelo comprador. Nesse caso, as relações não são valorizadas em forma de crédito (como anteriormente), mas pelas informações que são capazes de fornecer.

Em relação ao terceiro recurso, normas e sanções, o autor entende que quando uma norma é efetiva, devido a sanções internas/externas formais/informais, pode se constituir como KS por facilitar ações esperadas (no sentido de expectativa) pelo grupo, organização, comunidade ou sociedade. Coleman apresenta dois exemplos: (1) ao inibir atividades criminosas, uma norma efetiva torna possível um passeio à noite pela cidade; (2) uma norma que proporciona uma recompensa incentivadora do mérito de um aluno acaba facilitando o trabalho da escola. Em um grupo, uma norma prescritiva pode formar um importante KS ao fazer com que o autointeresse seja renunciado em favor dos interesses da coletividade. Em alguns casos, as normas são internalizadas; em outros, são mantidas por (a) recompensas externas para ações abnegadas ou (b) desaprovação devido a ações egoístas.

Quanto às estruturas sociais que facilitam o KS, o autor faz as seguintes distinções. Primeiro de tudo, o fechamento de redes sociais é uma propriedade das relações sociais que facilita as formas "obrigações e expectativas" e "normas e sanções". O "fechamento" (closure) 7 indicaria a existência de laços suficientes entre as pessoas, para que as normas sejam observadas por meio de sanções sociais. Com isso, tais normas seriam apropriadas pela comunidade, de modo que transações sejam facilitadas sem os recursos de contratos legais. Além disso, o fechamento de estruturas sociais seria importante para a confiabilidade da estrutura que permite a proliferação de obrigações e expectativas. Isso significa que a renúncia de uma obrigação se tornaria mais difícil porque a sanção será do grupo e sua reputação estaria em jogo. De outra forma, em uma estrutura aberta, a reputação não surgiria e sanções coletivas que assegurassem a lealdade não poderiam ser aplicadas. Por isso, seria possível afirmar que o fechamento cria lealdade em uma estrutura social. Em relação à forma de KS "canais de informação", o fechamento seria desfavorável a esse recurso por estabelecer informações redundantes (GRANOVETTER, 1973). Para compreender melhor esse facilitador (ou inibidor) de KS, reproduzimos a seguir as formas de rede sem (a) e com fechamento (b). 


\section{Figura 1- Rede sem fechamento (A) e com fechamento (B)}

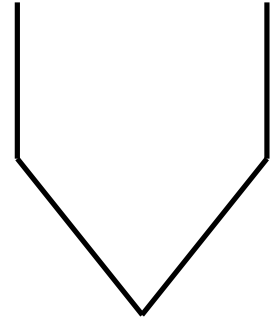

A

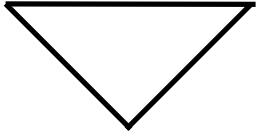

B

Fonte: Coleman (1988, p.S106).

Em segundo lugar, o autor denomina organização social apropriável (appropriable) qualquer organização criada para um objetivo e que possa ser apropriada para outros propósitos, constituindo-se num importante capital social para os membros, que têm a sua disposição recursos organizacionais que facilitam suas ações. De maneira geral, pode-se afirmar que a organização, uma vez criada para um conjunto de propósitos, também pode auxiliar a outros. Dessa forma, constitui-se um KS disponível para uso.

Coleman dá o exemplo dos estudantes sul-coreanos: os "círculos de estudo" clandestinos, que constituíam focos de resistência ao governo, foram criados por grupos de estudantes provenientes da mesma escola, cidade natal ou igreja. Nesse exemplo, a escola ou igreja, que tem seus objetivos, foi destinada a outros propósitos, constituindo-se num KS importante para os membros ao disponibilizar-lhes os recursos organizacionais necessários para a oposição política.

Coleman (1988, p.S109) faz ainda a distinção entre relações simplex e multiplex. Segundo ele, isso possibilita uma maior compreensão dos meios pelos quais o fechamento e a organização social apropriável facilitam o KS. Na relação simplex, os atores se relacionam apenas de uma forma (como vizinho, colega de trabalho, colegas de clube, correligionário etc.). Na relação multiplex, os atores estão ligados em mais de um desses contextos, ou seja, há uma sobreposição de redes sociais. Sua propriedade central é que permite que os recursos de um relacionamento possam ser reutilizados em outro. Geralmente, são recursos em forma de outras pessoas que têm obrigações num contexto e que podem ser acionadas para ajudar quando alguém estiver com problemas em outro contexto.

\section{Um tipo especial de capital social: o capital espiritual}

Capital espiritual (KE) ou KS religioso é um tipo especial de KS que se refere a aspectos deste capital relacionados à religião (estrutura social religiosa) ou espiritualidade. De modo geral, KE pode ser entendido como a influência de práticas, crenças, redes e instituições religiosas em indivíduos e organizações, tanto no âmbito econômico quanto social. Para Berger e Hegner (2003), KE se refere à conquista de poder, influência e prestígio, bem como à capacitação e aquisição de conhecimento, por um indivíduo ou uma organização, por participar de alguma tradição e/ou organização religiosa. Seguindo nessa direção, consideramos KE o grau de diversidade de recursos imersos em uma rede ou grupo religioso que os atores - principalmente, mas não necessariamente, membros - podem ter acesso para colocar em prática suas ações coletivas.

Até recentemente, pouca atenção foi dada à relação entre KS e religião, em parte porque as organizações religiosas eram vistas apenas como mais uma associação (SMIDT, 2003). Entretanto, o enfoque das pesquisas vem mudando devido ao reconhecimento, pelos economistas e por outros cientistas sociais, de que a religião 
não é um mero epifenômeno da economia (WUTHNOW, 1994) e nem está se tornando menos importante na sociedade (BERGER, 1996). Pesquisas sobre $\mathrm{KS}_{\mathrm{K}} \mathrm{KE}^{8}$ indicam que a religião é um fator importante na formação de redes sociais e para que haja confiança (IANNACCONE; KLICK, 2003; PUTNAM, 2000). Numa perspectiva complementar, Martes e Rodriguez (2005) afirmam que os laços religiosos podem estar subordinados a interesses econômicos e serem considerados recursos disponíveis. Segundo os autores, KE e confiança desenvolvidos no interior dos grupos religiosos podem se tornar fontes de vantagem competitiva no mercado, favorecendo o surgimento do empreendedorismo.

Além disso, há vários motivos para se estudar a relação entre KS e religião. As organizações religiosas oferecem serviços e recursos importantes para seus membros e para outras pessoas da comunidade, tais como aqueles relativos à saúde e aos suportes social e emocional. As doutrinas religiosas podem influenciar a visão de mundo das pessoas, suas prioridades de vida, sua socialização e suas preferências (no sentido econômico). Além do mais, o comportamento religioso pode criar KS por meio de ações de voluntariado e de caridade (SMIDT, 2003).

Estudos desenvolvidos no campo do investimento social privado no Brasil (e.g. LANDIM; SCALON, 2000) e nos Estados Unidos (e.g. VAN SLYKE; BROOKS, 2004) têm mostrado a relação entre práticas religiosas e disponibilidade de participação cívica, especialmente, no que se refere a doações e voluntariado. Tais estudos mostram que as motivações que levam indivíduos e empresas a investirem tempo e recursos no social estão mais relacionadas a aspectos subjetivos (laços pessoais, crença religiosa, compromisso político) do que racionais. Os incentivos fiscais influenciam muito pouco na decisão de investir na comunidade e não ampliam substancialmente os recursos investidos no espaço público.

Todos esses aspectos estimulam a diferenciação entre KE e outras formas de capital, como o KS, para que se evidencie mais precisamente o fenômeno religioso e sua relação com a vida econômica. Entre os pioneiros que aprofundam essa diferenciação está Max Weber.

As obras do pensador alemão - A ética protestante e A seita protestante e o espírito do capitalismo - foram fundadoras da análise da inscrição espiritual dos fenômenos econômicos e, por conseguinte, do KE. Na primeira, o autor mostra que algumas crenças do protestantismo ascético derivaram em normas (acompanhadas de suas sanções) que valorizaram o trabalho metódico e o consumo frugal. Tais fatores se estabeleceram como recursos aos indivíduos ao facilitar suas ações que tinham o propósito de diminuir a incerteza no seu estado de salvação. Na segunda obra, Weber insere em sua análise o papel da congregação - que não foi abordado na primeira -, cuja existência na vida dos membros foi fundamental para se manter a disciplina doutrinária do fiel. O tipo de estrutura social "fechamento" criou a forma de KS "normas e sanções". Assim, pertencer a uma congregação deu uma espécie de "certificado de qualificação moral", valorizado entre os comerciantes, possibilitando, desse modo, acesso ao crédito e garantia de confiabilidade na comunidade. Em outras palavras, a organização religiosa fomentou nos seus adeptos um tipo especial de KS propiciado pela reputação proveniente de normas morais e de sanções eficientes da congregação.

Mais recentemente, um dos pioneiros a indicar uma importante relação entre religião e KS foi Coleman (1988). O autor comparou dados de evasão escolar de escolas públicas, privadas e confessionais católicas. Nestas foram registradas as menores taxas de evasão, pois as comunidades nas quais a organização religiosa estava presente possuíam mais KS proveniente do fechamento baseado em relação multiplex,9 o que não ocorria nas comunidades de outras escolas.

Putnam (1993) também mostrou que historicamente as black churches foram uma fonte de KS para os afroamericanos, fornecendo infraestrutura organizacional para a mobilização política do movimento dos direitos civis. O autor cita estudos que mostram que a igreja é um recurso importante para o engajamento político entre os negros, pois através dela estes desenvolvem habilidades políticas e fazem contatos com pessoas e outros movimentos. $\mathrm{O}$ autor observa que algumas igrejas criam bancos de empregos e servem como agências informais de crédito, usando seu capital "reputacional" e responsabilizando-se por membros, que podem ser excondenados, viciados em drogas ou que tenham abandonado os estudos. Nesses casos, a igreja não fornece apenas redes de referência, mas credenciais que funcionam como garantia para empregadores e instituições bancárias, gerando confiança. 
Woodberry (2003) reforça a proposta de empregar o conceito de KE. O autor afirma que os grupos religiosos geralmente enfatizam que a relação com Deus é a razão de existir do grupo e que o enfoque de suas atividades deve ser o de valorizar e pôr em prática esse relacionamento. Dessa forma, um grupo religioso funciona de maneira distinta de um mero clube social ou, ainda, de uma organização econômica. Um das consequências disso é que os membros do grupo geralmente disponibilizam recursos espirituais (crenças, símbolos) e organizacionais a qualquer um que os procure, mesmo não sendo um de seus membros efetivos. Portanto, não são observadas normas de reciprocidade, pelo menos, num primeiro momento, nem se tem a certeza de que a norma será observada.

Precisamos nos ater um pouco mais a esse ponto. Coleman descreve o mecanismo social de funcionamento do KS, fazendo uma analogia com a obtenção de crédito. Porém, Hsu (2006) chama a atenção para o fato de que o autor não aborda questões fundamentais relacionadas ao parágrafo anterior. Exemplo: Como a dinâmica da obtenção de crédito é iniciada? Por que atores dariam o primeiro passo para compartilhar recursos? Por que se confiaria em alguém que não tem garantias (por não pertencer à organização e, por isso, não estar sujeito às sanções) de que a confiança será recíproca? A resposta é que a religião pode fornecer as bases para a primeira obtenção de crédito, por doar - seja recursos espirituais ou materiais - em primeiro lugar. Desse modo, é pertinente concluir que as organizações religiosas podem ser uma fonte especial de normas de reciprocidade e confiança; portanto, geradoras de um tipo específico de KS que, ao que tudo indica, é mais aberto a quem está em situação desfavorável na sociedade do que outras formas de KS (COLEMAN, 2003). Trata-se, assim, de um importante recurso para a mobilidade social.

Uma característica original da formação de KS por organizações religiosas é a capacidade de prover e manter a reciprocidade entre os atores (HARRIS, 2003). Isso, em parte, pode ser atribuído à maior expectativa de retribuição nesse tipo de organização do que em outras não religiosas, dada no compartilhamento de valores transcendentais que estabelecem recompensas para a cooperação e punições para ações egoístas. Além disso, diz o autor, formas religiosas de cooperação de grupo podem contar com incentivos não materiais - geralmente, enraizados em crenças da comunidade religiosa - para induzir os atores a cooperarem, enquanto as formas seculares devem empregar com maior intensidade incentivos materiais.

Essas características do KS religioso ou KE não invalidam o uso do modelo de Coleman para a análise dos dados de campo das organizações religiosas. Pelo contrário, o modelo é extremamente útil ao nos ajudar a examinar a estrutura religiosa como um recurso para a ação social ou, mais especificamente, no caso deste texto, para a ação empreendedora.

\section{Procedimentos metodológicos}

A pesquisa está estruturada em torno de dois estudos de caso qualitativos, analisados a partir de uma perspectiva comparada. Em cada um deles examinamos o papel de empreendedores ligados a organizações religiosas: a Igreja Renascer em Cristo (IRC) e a Igreja Católica, por meio do Movimento dos Focolares (MF) e de sua proposta econômica denominada economia de comunhão (EdC). ${ }^{10}$ Ambas as organizações possuem suas sedes em São Paulo, Brasil. Escolhemos o estudo comparativo porque permite conhecer tanto as características comuns quantos as específicas e, também, por esclarecer como se relacionam certos processos, aparentemente, contraditórios ou distintos (MARIZ, 2001).

A opção pelo desenho de pesquisa é consoante com a tendência indicada por Wuthnow (2005) de que os trabalhos acadêmicos recentes que analisam a relação entre vida econômica e religião são predominantemente qualitativos e utilizam elementos característicos da pesquisa etnográfica. Entendemos estudo de caso como uma investigação sobre um "fenômeno contemporâneo dentro do contexto de sua vida real, especialmente, quando os limites entre fenômeno e contexto não são claramente evidentes" (YIN, 1984, p.13). De modo complementar, o estudo de caso pode ser tomado como um processo que procura descrever e analisar o fenômeno pesquisado em termos qualitativos, complexos e compreensivos e seu "deslocamento" num dado período de tempo (MERRIAM, 1998). Esse desenho é particularmente apropriado para situações em que (a) é impossível separar as variáveis do fenômeno do seu contexto e (b) problemas/questões de pesquisa são do tipo "como" e "por que", em situações nas quais o pesquisador não detém controle sobre os eventos (YIN, 1984). 
A escolha das duas organizações religiosas se justifica por: (i) serem atuantes há mais de 15 anos; (ii) contemplarem o segmento de empreendedores, objeto desse estudo; (iii) difundirem um discurso que possui especificidades voltadas para tal segmento; e (iv) criarem e disponibilizarem recursos organizacionais específicos para ele, tais como cultos para empresários, grupos de pessoas específicas para darem apoio informacional, emocional e espiritual (SERAFIM; MARTES, 2007). Além desses aspectos, o Polo Spartaco, um conjunto de empresas ligadas à Igreja Católica, tem no Brasil 125 milhões de adeptos (dados do Censo 2000 do IBGE), embora, de modo geral, não seja reconhecido na literatura afim como uma organização cuja doutrina promove e incentiva o empreendedor ou homem de negócios. A IRC, por sua vez, foi selecionada por servir como um contraponto à primeira experiência: é uma igreja recente, reúne apenas 120 mil fiéis e seu discurso é bastante claro e diretamente relacionado à promoção do sucesso empresarial.

Para a coleta de dados, realizada no período de 2006 a 2008, utilizamos três técnicas. A primeira, a observação não participante, consistiu de visitas às organizações religiosas (Mariápolis Ginetta, um dos locais onde habitam membros do MF, em em dois templos da Renascer), às associações empresariais (Associação Nacional por uma Economia de Comunhão - Anpec-EdC, do MF; e a Associação Renascer de Empresários e Profissionais Evangélicos - Arepe, da IRC), além de participação em cultos, missas, reuniões de trabalho, encontros de empresários e conversas informais com seus participantes. As observações e conversas foram registradas num caderno de campo. A segunda técnica empregada foi a entrevista em profundidade com religiosos e leigos católicos, bispos e pastores evangélicos e também com empresários de ambas as igrejas. No total, foram 16 entrevistas, registradas num gravador digital, para análise posterior. A escolha dos entrevistados foi pelo método "bola de neve", no qual os primeiros informantes (selecionados por sua importância e envolvimento em projetos de apoio ao empreendedorismo nas respectivas organizações religiosas, bem como pela facilidade de contato) recomendam outros, conforme suas competências em atender às solicitações dos pesquisadores; procedimento repetido em relação a novas inclusões. A terceira técnica empregada, a de análise documental, partiu da observação de artigos e reportagens de jornais e revistas, de fôlderes, sites, material publicitário, memorandos internos, fotos e do regimento das empresas e associações. Também foram consultados os jornais Folha de São Paulo, Estado de São Paulo, O Globo, as revistas Veja e Istoé e sites de notícias evangélicos (como o Gospel+); nestes casos, recorrendo à tecnologia RSS (Really Simple Syndication), que serve para agregar conteúdo de sites e blogs.

Finalmente, por adotarmos uma perspectiva comparativa, descrevemos e analisamos separadamente cada organização. Em seguida, comparamos as seguintes dimensões do capital social criado para os empreendedores: "fechamento" de redes sociais, organização social apropriada, obrigações e normas, canais de informações (COLEMAN, 1988, conforme descrito anteriormente), estruturas de plausibilidade e redes religiosas de ajuda mútua.

Em relação às limitações da pesquisa, deve-se considerar que os empresários entrevistados ligados à IRC foram escolhidos pelo bispo que estava acompanhando a pesquisa. Os problemas com a Justiça brasileira, em dezembro de 2006, e a prisão do casal que lidera a IRC nos EUA, em janeiro de 2007, fizeram com que a partir de então os contatos se tornassem bastante difíceis.

\section{Atando os laços}

A IRC e o MF têm em comum a apropriação de suas organizações para outros fins que vão além dos objetivos originais, como o incentivo e apoio ao empreendedorismo, colocando à disposição seus recursos organizacionais. Essa característica da estrutura social, denominada por Coleman (1988) "organização social apropriável", constitui um importante facilitador de KE. Por exemplo, no caso da IRC foi utilizado o espaço da própria igreja para realizar um curso de finanças, além de ter sido organizado um seminário sobre a concepção dos planos de negócios e para promover "network" entre os participantes. No MF, seus espaços também foram utilizados para outros propósitos além do exclusivamente religioso, como, por exemplo, para uma feira de exposições das empresas de EdC durante o congresso anual, para a organização e o desenvolvimento do polo empresarial e para as reuniões bimestrais do workshop da EdC, ocasiões em que foram discutidos e avaliados projetos para o desenvolvimento da EdC no âmbito empresarial. Em ambas as organizações não há restrições 
importantes a que tais apropriações ocorram. Além do mais, pelo que se pôde perceber na pesquisa, esse facilitador de KE está mais desenvolvido no MF, devido ao seu maior tamanho e abrangência e à quantidade de espaços que podem ser utilizados, como acontece na Mariápolis Ginetta. ${ }^{11}$

Outro facilitador de KE, o "fechamento de redes sociais", refere-se aos laços sociais entre as pessoas, em relação aos quais as normas se tornam efetivas por meio da aplicação de sanções quando essas são descumpridas. No caso das organizações pesquisadas, pode-se considerar que as redes sociais de ambas possuem fechamento porque os laços sociais estabelecidos são suficientes para que as sanções tenham efeito sobre a observância das normas, o que é bastante comum em organizações religiosas. Em decorrência disso, a confiança nas estruturas sociais é maior, o que facilita as formas de KS "normas e sanções" e "obrigações e expectativas". Pode-se perceber, entretanto, que mais uma vez o MF possui esse facilitador mais proeminente do que a IRC. Esse fator pode ser atribuído ao estilo mais comunitário de convivência do MF, o que acontece de forma limitada na IRC. Enquanto ser membro do MF equivale a participar de alguma atividade ou pequeno grupo, ser membro da IRC pode significar tanto participar de um grupo quanto ir apenas ao culto, o que garante certo grau de anonimato. Neste caso, as sanções coletivas são aplicadas de forma limitada. Além do mais, o sistema de comunicação do MF é mais eficiente, e, devido a isso, há um sistema de reconhecimento dos membros - e não membros, como visitantes, simpatizantes, etc. - também mais eficiente.

Podemos acrescentar mais um item facilitador do KE relacionado às "normas" e que não foi comentado por Coleman. Ao mesmo tempo em que o fechamento das redes sociais facilita as sanções externas ao indivíduo como a sanção do grupo em relação a um comportamento desviante às normas -, também facilita as sanções internas (subjetivas), na medida em que promove as "estruturas de plausibilidade", como analisado por Berger (1996). Essas estruturas fornecem uma concepção de mundo ao indivíduo e sua força depende da estrutura social que sustenta a plausibilidade em questão. Ainda de acordo com Berger, como as afirmações religiosas do mundo são, por sua natureza, incapazes de ter seu apoio em nossa própria experiência dos sentidos, dependem, portanto, inteiramente do suporte social (por exemplo, do grupo, das pessoas com as quais conversamos etc.). A realidade se mantém viva - ou seja, a plausibilidade do discurso, dos recursos simbólicos, do funcionamento do mundo material e espiritual, ou, de modo mais geral, da fé - porque os outros, com os quais o indivíduo convive e interage nas redes sociais, afirmam essa realidade e compartilham das mesmas crenças. Tal realidade, aceita pelo indivíduo, possui um conjunto de normas efetivas devido a sanções criadas coletivamente, mas que o próprio indivíduo também se impõe.

As organizações religiosas talvez sejam atualmente o principal sistema social do tipo facilitador de normas eficientes por sanções internas. Neste estudo, tanto a IRC quanto o MF possuem fortes estruturas de plausibilidade. Quanto à IRC, podem ser citados como exemplos os testemunhos de milagres, curas e mudanças radicais de vida, a valorização de um engajamento que requer prestar serviços para a igreja - portanto, estar mais em contato com seus pares -, bem como o forte incentivo a ouvir músicas gospel, a assistir à Rede Gospel de Televisão, ${ }^{12}$ ouvir rádios gospel e a utilizar o portal igospel.com.br como fonte de informação e entretenimento. No que diz respeito ao MF, destacam-se os testemunhos de atos de amor e de sacrifício, a participação intensiva nos encontros e setores do movimento, a valorização da missa cotidiana, o incentivo às experiências (ou seja, a permanência por um determinado período) nas Mariápolis Permanentes, além do estímulo à leitura de obras escritas por membros e simpatizantes do MF, entre outros exemplos.

Voltando agora às formas de KE, os "canais de informação" possuem uma função determinante nos casos estudados. Coleman adverte que a informação inerente às estruturas sociais tem como função facilitar a ação, o que, contudo, envolve custos, pois requer a atenção, um recurso escasso. Entretanto, nessas organizações religiosas, a atenção é um dos recursos mais abundantes, inclusive para estranhos, o que torna os canais de informação um KE bastante afluente. Por exemplo, os empreendedores podem recorrer à rede religiosa para obter informações e conselhos sobre como proceder em relação a determinado assunto da empresa. As necessidades de um empreendedor também circulam nesses canais, fazendo com que pessoas se ofereçam para ajudá-lo. Nesse sentido, cabe lembrar que o empreendedor ainda informa sobre ofertas de emprego em sua empresa, sendo, por outro lado, informado sobre pessoas que estejam à procura de trabalho. 
O MF criou um recurso que, ao mesmo tempo, utiliza e fortalece os canais de informação. As comissões regionais de $\mathrm{EdC}$ - grupos que coordenam as atividades da economia de comunhão numa determinada região utilizam os canais para receber informações das redes do movimento e alimentá-los com novas informações, no intuito de dar apoio aos empreendedores. As comissões podem servir ainda como espécies de "avalistas", porque informam não apenas a situação financeira de uma empresa, mas também fornecem indicadores de confiabilidade para as empresas que estão em sua lista, facilitando, por exemplo a concessão de empréstimos entre estas.

Outro aspecto relevante é que a estrutura de fechamento das redes sociais analisadas contribui com as formas de KS em termos de "obrigações e expectativas" e "normas e sanções". Em relação a esse último aspecto, as normas prevalecentes em ambas as organizações pesquisadas incentivam, por exemplo, o estilo de vida ascético e a preponderância do interesse coletivo sobre o individual. Para isso, são aplicadas sanções contra o comportamento egoísta ${ }^{13}$ e concedidos prêmios para a reciprocidade e as ações gratuitas (ou altruístas). Dessa forma, favorece-se a coesão social dessas organizações. É importante destacar que as organizações religiosas são uma fonte especial e potente de normas de reciprocidade e confiança, por possuírem uma característica forte de comunidade - com o fechamento de redes sociais.

Aqui há um ponto importante a ser destacado. A confiança e a reciprocidade entre as pessoas e no ambiente social aumentam de acordo com as normas de tais organizações devido a mais dois fatores, além dos fatores anteriores: (i) o ato de gratuidade, por ser identificado como "não autointeressado", tende a incentivar a confiança e a reciprocidade do outro, pois a realização desse ato é uma escolha da pessoa, envolvendo risco, esforço e uma confiança inicial, uma vez que ela tem a liberdade de optar por não realizá-lo; (ii) a coesão proveniente dessas normas permite que os agentes se reconheçam o suficiente para identificar os oportunistas, fazendo com que a confiabilidade seja reforçada, num processo de realimentação (feedback).

Além disso, as normas são interiorizadas - as estruturas de plausibilidade exercem um importante papel nesse sentido, conforme visto anteriormente - ou mantidas por prêmios externos, com o reconhecimento público da virtude do indivíduo ou a desaprovação do grupo a certas atitudes incompatíveis com o interesse coletivo. Sobre essa forma de KS, não foi possível apreender nenhuma diferenciação essencial entre as duas organizações pesquisadas. Apenas observou-se que no MF as normas de gratuidade e reciprocidade são especialmente destacadas, principalmente, pela maior ênfase no amor mútuo do que na IRC, onde esse termo é pouco mencionado.

Em relação à forma de KS "obrigações e expectativas", nas organizações religiosas pesquisadas, a confiabilidade do ambiente social e a abrangência das obrigações - dois pressupostos fundamentais - estão amplamente presentes, por conta das normas efetivas que facilitam a confiança entre os membros e a garantia da reciprocidade generalizada dessas obrigações. De fato, numa organização religiosa, a reciprocidade amparada em valores transcendentes - é a forma de relacionamento mais esperada, por despertar nos atores expectativas mútuas de recompensa aos que cooperarem e de punições divinas para os que não o fizerem. Como já mencionado, Coleman descreve o mecanismo social que cria as obrigações mútuas e a reciprocidade através de um sistema de "crédito": se $A$ faz algo para $B, A$ confia que $B$ irá retribuir, gerando expectativa em $A$ e obrigação em $B$.

Um ponto fundamental a ser compreendido é como esse mecanismo se inicia, ou seja, quem começará a partilhar os recursos para que as expectativas e obrigações sejam geradas. $\mathrm{O}$ autor não aborda esse problema, mas a resposta pode estar, nos casos aqui estudados, nas organizações religiosas, sempre prontas a tomar a iniciativa, desencadeando dessa forma a dinâmica da obtenção do "crédito". Em ambas as organizações, tais iniciativa e dinâmicas estão muito presentes. A ajuda mútua - abordada anteriormente - faz parte dessa dinâmica, e pode ser compreendida, ao adotarmos essa perspectiva de Coleman (1988, p.S104), na ideia de que os agentes estão "imersos em um sistema de débito e crédito".

Esse "dar em primeiro lugar" tem um papel importante em relação a estranhos (outsiders) às respectivas organizações. Relatos de empreendedores deixam clara a importância dessa propriedade das relações sociais das organizações religiosas. Para ilustrar, um empreendedor vinculado à IRC afirmou que a organização o acolheu sem condicionantes e o ajudou a superar a dependência química. A gratidão que ele menciona diante 
do que denomina generosidade da igreja faz com que se sinta sempre em débito com ela, o que, por sua vez, traduz-se em participação constante nos cultos, trabalhos voluntários, dízimos e ofertas, todos como uma forma de retribuição.

Foi exatamente essa constatação de campo que chamou a atenção para o que consideramos uma limitação do conceito de KS de Coleman, abrindo espaço para a aplicação de outra abordagem que complementa a explicação do mecanismo da reciprocidade: o sistema de dádiva (dar - receber - retribuir, segundo Mauss, 2003). Do modo como Coleman expõe o seu modelo de "crédito" (expectativa) e "débito" (obrigação), é possível interpretar que haverá, na linha do horizonte, uma equivalência entre o "crédito" recebido e o "débito" pago. Isso é bem provável que aconteça em outras organizações, mas fica muito difícil evidenciar na a dinâmica do "crédito" nas organizações religiosas, pela constatação empírica de que, pelo menos, para os empreendedores entrevistados, não chegará o momento em que ficarão quites com a organização. Eles se sentem sempre em débito, por mais que doem seu tempo, dinheiro e conhecimento. Esse desequilíbrio ou o "juro impagável" entre "crédito" e "débito" não é entendido por eles como anomalia, ao contrário, é considerado absolutamente normal, o que os leva ainda a querer "lucrar mais para dar mais", a acreditar que "o segredo de ter mais é repartir" e que "quando a pessoa se dá por alegria, Deus a abençoa". Em ambas as organizações, a doação de si não tem "limite de crédito".

Outra constatação foi a de que os empreendedores obtêm vantagens relativas provenientes do KE, ${ }^{14}$ mas muitos parecem estar mais preocupados em dar apoio do que em receber. Eles se oferecem para criar sites, para informar os atuais ou pretendentes empresários, constituem grupos que funcionam como consultoria, alguns emprestam dinheiro sem garantias formais de devolução e sem intenção de cobrar esse favor no futuro, além de ajudarem nas atividades corriqueiras das organizações. Realizam isso tudo - segundo os dados coletados - não apenas por dever religioso, muito menos por interesse econômico ou material, mas pelo prazer de retribuir. Essas ações, motivadas pela dádiva, estabelecem relações de reciprocidade generalizada - criam um KE que se manifesta em recursos organizacionais para outros empreendedores que, ao serem beneficiados pessoal e/ou profissionalmente, buscam retribuir, criando assim um círculo virtuoso de $\mathrm{KE}$, como aconteceu na IRC e no MF.

No caso da IRC - por meio de seu KE construído ao longo dos anos -, alguns empresários começaram a frequentá-la à procura de soluções para seus problemas pessoais, e por conta de sua conversão - mudança de estilo de vida, êxito na superação de algum vício, entre outros motivos - se dispuseram a criar KE mais específico para outros empreendedores. Isso também como forma de agradecimento à IRC e como uma "resposta" à decisão de Estevam Hernandes, seu fundador, de formar um ministério específico para esses profissionais. Com isso, estabeleceu-se um segmento importante que, estrategicamente, foi incorporado à estrutura formal da Igreja.

No MF também houve a utilização de KE já existente. A sua mobilização para a construção de KE mais específico foi fruto de uma proposta econômica - a EdC - lançada como uma missão para seus membros, os quais deveriam "doar sua vida" para esse projeto. No MF, o sistema de dádiva é mais sistematizado, inclusive, com intelectuais ligados ao movimento desenvolvendo teorias e pesquisas sobre a prática da comunhão de bens, que nada mais é do que um sistema especial de dádiva.

Voltando a Coleman (1988), podemos afirmar que, quando a organização religiosa "dá primeiro", ela ativa o mecanismo de "crédito" descrito pelo autor. No entanto, paralelamente, ela ativa o sistema da dádiva, geradora da assimetria entre dar e receber, que se transforma numa poderosa fonte de KE. Na verdade, Coleman não considera que entre expectativa e obrigação possa haver um "juro impagável" - considerado não pela parte de quem deu, mas pela parte de quem recebeu - típico do sistema de dádiva e manifestado no sentimento do fiel de que estará sempre em dívida com a organização, por acreditar que recebe mais do que dá, como expresso na frase "eu devo muito a ela". ${ }^{15}$ Nesses casos, a dívida não se relaciona com o valor monetário do que se teria recebido em termos de serviços, pois não se busca uma equivalência ou uma simetria de relações, como é comum no sistema de mercado. O que está em jogo é o estabelecimento de vínculos sociais que necessariamente se traduzem numa reciprocidade assimétrica, em que o papel da dívida se torna fundamental. É nesse "desequilíbrio" - em que o empreendedor dá sem estabelecer um contrato mercantil ou equivalente 
monetário com a organização - que reside uma fonte importante de KE, na medida em que é um poderoso gerador de vínculos sociais e de recursos organizacionais.

A riqueza do KE nas organizações religiosas é explicada, em parte, discordando de Coleman. $\mathrm{O}$ autor apresenta como uma propriedade de KS - e que o diferencia das outras formas de capital - a possibilidade dos atores que geram KS captarem apenas uma pequena parte de seu benefício, o que levaria ao subinvestimento de KS. De acordo com o critério da ação racional - no sentido de adequação entre meios e fins -, a análise está correta, mas do ponto de vista do sistema de dádiva, a afirmação pode ser contestada ou considerada incompleta. Discordamos de Coleman ao notar em campo um forte investimento pelos entrevistados em KS "para os outros" - de modo intencional. Isso ocorre devido à norma da gratuidade, segundo a qual as pessoas trabalham voluntariamente para a criação, manutenção e desenvolvimento de recursos organizacionais para outros empreendedores, sem qualquer garantia de que, em troca, serão beneficiadas.

Uma diferença essencial que pode ser estabelecida entre a IRC e o MF é que este, por meio da EdC, propõe que o mercado seja considerado uma instituição na qual é possível abrir espaço para o sistema de dádiva, tanto no interior de suas organizações, quanto na forma de redistribuição internacional do lucro para os mais pobres. ${ }^{16}$ Propõe ainda - e tenta aplicar na prática - que os vínculos sociais não estejam apenas a serviço dos bens econômicos - como no sistema de pura troca mercantil -, mas que os mesmos bens possam servir como meio para que se criem e se mantenham vínculos, de modo que as trocas mercantis não sejam dissociadas do relacionamento humano.

Voltando para o empreendedor, como a teoria do KE chama a atenção para os recursos inerentes às relações entre as pessoas, é interessante considerá-lo menos como um agente engajado em seu empreendimento (ou como um indivíduo desconectado) e mais, muito mais, como um agente imerso numa comunidade. As organizações religiosas oferecem uma comunidade - em maior extensão no MF - onde o sistema de dádiva é mais incentivado ou vivido do que em um sistema burocrático ou de mercado. Com isso, há maior nível de KE por conta do fortalecimento dos laços sociais que o sistema de dádiva promove, o que acarreta, por sua vez, maior lealdade ou confiabilidade no sistema. Estar imerso em uma comunidade significa que o empreendedor está imerso em vínculos sociais que influenciam de modo contínuo suas motivações e os sentidos de suas ações, inclusive, a econômica. Para finalizar, no sistema da dádiva, o empreendedor pode ser nomeado o "empreendedor do dom", pois ele faz uma aposta de confiança nos outros, no mundo, possuindo a capacidade de "abrir-se à incerteza quanto ao retorno que constitui a generosidade e o dom primeiros, em cuja ausência não haveria muito, exatamente nada, em vez de alguma coisa" (CAILLÉ, 2002, p.58).

\section{Conclusão}

Procuramos mostrar que as estruturas religiosas das organizações investigadas formam um tipo especial de capital social, denominado capital espiritual - porque de origem religiosa - por meio do "fechamento" de redes sociais, organização social apropriável, obrigações e normas, canais de informações e redes religiosas de ajuda mútua. O KE apresentou características específicas, que não são suficientemente abordadas na teoria do capital social, como a formulada por Coleman (1988). Por fim, identificamos diferenças e semelhanças de formação de $\mathrm{KE}$ entre as organizações religiosas investigadas, tendo como enfoque o empreendedor-membro.

Com base em abordagens sobre a dádiva ${ }^{17}$ nas sociedades modernas, buscamos evidenciar algumas lacunas no trabalho de Coleman. $\mathrm{Na}$ análise dos dados ficou evidente que muitos empreendedores faziam referência ao desejo de se dedicarem à atividade empreendedora com o intuito de doarem cada vez mais bens materiais para a igreja (no caso da IRC) e para o projeto de EdC (no caso do MF), com uma "disposição de espírito" que não parecia relacionada com o sentimento de dever no seu sentido ético. Além disso, como já destacado, eles se dedicavam, consideravelmente, a trabalhos não remunerados de voluntariado. Isto é, doavam parte de seu tempo para ações de apoio em suas respectivas organizações religiosas. Em outras palavras, muitos empresários, ao se engajarem, contribuem para o funcionamento do sistema de dádiva, e o motivo para participarem desse sistema não está no âmbito do interesse, mas no âmbito simbólico, no qual a recompensa é intrínseca à ação, no ato em si e no que ele representa. Por sua vez, as ações nesse sistema estão voltadas para a 
criação e manutenção dos vínculos sociais, por meio da dinâmica do dar - receber - retribuir, de maneira livre e obrigatória, simultaneamente.

Se o capital social é formado pelos recursos disponibilizados por meio das relações sociais e a dádiva é o sistema de estabelecimento de vínculos por excelência, é razoável supor que a dádiva exerce um papel fundamental na formação do capital social. Além disso, como as organizações religiosas são atualmente os sistemas sociais que mais incentivam a dádiva - e o capital social é um importante potencializador de ações econômicas - há aqui uma interessante forma de abordar a relação entre a esfera religiosa e a esfera econômica. Em outras palavras, de compreender melhor as consequências econômicas da dádiva. 


\section{Referências}

BARON, R. A.; MARKMAM, G. D. Beyond social capital: the role of entrepreneurs' social competence in their financial success. Journal of Business Venturing, v.18, p.41-60, 2003.

BARON, S.; FIELD, J.; SCHÜLLER, T. (Ed.). Social capital: critical perspectives. Oxford: Oxford University Press, 2000.

BERGER, P. L. Rumor de anjos: a sociedade moderna e a redescoberta do sobrenatural. Petrópolis, RJ: Vozes, 1996.

BERGER, P. L.; HEGNER, R. W. Spiritual capital in comparative perspective. 2003. Disponível em: <http://tinyurl.com/bergerke>. Acesso em: 10 set. 2005.

BOURDIEU, P. The forms of capital. In: RICHARDSON, J. (Ed.). Handbook of theory and research for the sociology of education. New York: Greenwood Press, p.214-258, 1986.

CAILLÉ, A. Antropologia do dom: o terceiro paradigma. Petrópolis, RJ: Vozes, 2002.

CHANG, H-J. Economic development. In: BECKERT, J.; ZAFIROVSKI. International encyclopedia of economic sociology. London: Routledge, p.176-181, 2006.

COLEMAN, James S. Social capital in the creation of human capital. The American Journal of Sociology, v.94, p.S95S120, 1988.

COLEMAN, John A. Religious social capital: its nature, social locations, and limits. In: SMIDT, C. (Ed.). Religion as social capital: producing the common good. Texas: Baylor University Press, p.33-47, p. 2003.

FUKUYAMA, F. Social capital, civil society and development. Third World Quarterly, v. 22, n. 1, p. 7-20, 2001.

GODBOUT, J. T. Introdução à dádiva. Revista Brasileira de Ciências Sociais, v.13, n.38, p.39-52, 1998.

O espírito da dádiva. Rio de Janeiro: Editora Fundação Getulio Vargas, 1999.

GRANOVETTER, M. S. The strength of weak ties. The American Journal of Sociology, v.78, n.6, p.1360-1380, 1973.

Economic action and social structure: the problem of embeddedness. American Journal of Sociology, v. 91, n. 3, p. 481-510, 1985.

GREELEY, A. Coleman revisited: religious structures as a source of social capital. American Behavioral Scientist, v.40, n.5, p.587-594, 1997.

HARRIS, F. Ties that bind and flourish: religion as social capital in African-American politics and society. In: SMIDT, C. (Ed.). Religion as social capital: producing the common good. Texas: Baylor University Press, p.121-137, 2003.

HSU, B. Social capital as a link between religion and the economy. The International Scope Review, v.8, n.13, p.1-23, 2006.

IANNACCONE, L. R.; KLICK, J. Spiritual capital: an introduction and literature review. 2003. Disponível em: $<$ http://tinyurl.com/iannaccone>. Acesso em: 10 set. 2005.

LANDIM, L.; SCALON, M. C. Doações e trabalho voluntário no Brasil - uma pesquisa. Rio de Janeiro: 7 Letras, 2000.

LEITE, Kelen Christina. Economia de comunhão: uma mudança cultural e política na construção do princípio da reciprocidade nas relações econômicas. 2005. Tese (Doutorado em Ciências Sociais) - Programa de Pós-Graduação em Ciências Sociais do Centro de Educação e Ciências Humanas da Universidade Federal de São Carlos, São Carlos, 2005.

LIN, N. Building a network theory of social capital. Connections, v.22, n.1, p.28-51, 1999.

Social capital. In: BECKERT, J.; ZAFIROVSKI. International encyclopedia of economic sociology. London: Routledge, p.604-612, 2006.

MARIZ, C. Pentecostalismo e renovação católica e comunidade de base: uma análise comparada. Cadernos Ceris, Rio de Janeiro, v.1, n.2, p.11-42, 2001.

MARTES, A. C. B.; RODRIGUEZ, C. L. Afiliação religiosa e empreendedorismo étnico: o caso dos brasileiros nos Estados Unidos. In: SOUZA, E. C. L.; GUIMARÃES, T. A. Empreendedorismo além do plano de negócios. São Paulo: Atlas, p.67-88, 2005.

MAUSS, M. Ensaio sobre a dádiva: forma e razão da troca nas sociedades arcaicas. In: Sociologia e antropologia. São Paulo: Cosac Naify, p.185-314, 2003. 
MERRIAM, S. Qualitative research and case study applications in education. 2.ed. San Francisco: Jossey-Bass, 1998.

NAHAPIET, J.; GHOSHAL, S. Social capital, intellectual capital, and the organizational advantage. Academy of Management Review, v.23, n.2, p.242-266, 1998.

OLSON, M. A lógica da ação coletiva: os benefícios públicos de uma teoria dos grupos sociais. São Paulo: Edusp, 1999.

PORTES, A. Social capital: its origins and applications in modern sociology. Annual Review of Sociology, n.24, p.1-24, 1998.

PUTNAM, R. D. The prosperous community: social capital and public life. The American Prospect, n. 13 , Spring 1993.

Bowling Alone: The Collapse and Revival of American Community. New York: Simon \& Schuster, 2000.

SERAFIM, M. C. Religião e o "espírito" empreendedor. In: ENCONTRO DA ASSOCIAÇÃO NACIONAL DE PÓSGRADUAÇÃO E PESQUISA EM ADMINISTRAÇÃO, 32., 2008, Rio de Janeiro. Anais... Rio de Janeiro: ANPAD, 2008.

; MARTES, A. C. B. Sobre esta pedra edificarei a minha empresa: organizações religiosas e o incentivo ao empreendedorismo. In: ENCONTRO DA ASSOCIAÇÃO NACIONAL DE PÓS-GRADUAÇÃO E PESQUISA EM ADMINISTRAÇÃO, 31., 2007, Rio de Janeiro. Anais... Rio de Janeiro: ANPAD, 2007.

SMIDT, C. (Ed.). Religion as social capital: producing the common good. Texas: Baylor University Press, 2003.

VAN SLYKE, D.M.; BROOKS, A. C. Why do people give? New evidences and strategies for nonprofit managers. American Review of Public Administration v. 35, n. 3, 199-222, 2004.

WOODBERRY, R. D. Researching spiritual capital: promises and pitfulls. 2003. Disponível em: <http://www.metanexus.net/spiritual_capital/pdf/woodberry.pdf>. Acesso em: 10 set. 2005.

WUTHNOW, R. Religion and economic life. In: SMELSER, N. J.; SWEDBERG, R. (Eds.). The handbook of economic sociology. Princeton, N.J.: Princeton University Press, p. 620-646, 1994.

New directions in the study of religion and economic life. In: SMELSER, N. J.; SWEDBERG, R. (Ed.). The handbook of economic sociology. $2^{\text {nd }}$ ed. Princeton, N.J.: Princeton University Press, p.603-626, 2005.

YIN, R. K. Case study research. Newbury Park, California: Sage Publications, 1984.

${ }^{1} \mathrm{O}$ autor exemplifica da seguinte forma "[...] assim como o conceito de 'cadeira' identifica certos objetos físicos pelas suas funções, a despeito de suas diferenças na forma, aparência e construção" (COLEMAN, 1988, p.S101), nós acrescentaríamos "e de quem sentará nela" para destacar os possuidores do KS.

${ }^{2}$ Como relata Greeley (1997), a intenção de Coleman ao trabalhar esse conceito era acrescentá-lo como parte de um projeto, que ele se ocupou até sua morte, de construir uma ponte entre a sociologia e a economia, particularmente a economia da Escola de Chicago.

${ }^{3}$ É a supersocialização do ator, também criticada por Granovetter (1985).

${ }^{4}$ Portes (1998) critica o trabalho de Coleman ao afirmar que seu conceito é vago, o que permitiria considerar como KS vários processos diferentes e até mesmo contraditórios. Para esse autor, Coleman considera na mesma categoria alguns dos mecanismos que geram KS (tais como a expectativa de reciprocidade e a sanção do grupo para o cumprimento de normas), as consequências de possuí-lo (acesso a informações) e o contexto que os materializa (organização social "apropriável"). Com isso, ainda segundo Portes, Coleman deixou de realizar a seguinte distinção para um tratamento sistemático do conceito: (i) os possuidores de KS; (ii) as fontes de KS; (iii) os recursos em si. Na nossa leitura, Portes faz uma análise apressada do trabalho de Coleman. Apesar de mencionar a característica básica de seu conceito de KS como função, parece que isso foge a Portes. Por exemplo, os "canais de informação" para Coleman são uma forma e não uma consequência (como Portes acredita que deveriam ser) de KS, por entender que nesse aspecto as relações sociais mantidas são importantes pelas informações que são capazes de fornecer; ou seja, possuem uma função que tem como consequência a facilitação da ação do indivíduo. Além disso, o modelo de Coleman deixa claro em sua análise do capital social (dentro e fora da família) quem possui KS, bem como suas fontes e recursos.

${ }^{5}$ Em seus primeiros estudos, Putnam recorre frequentemente a Coleman.

${ }^{6}$ Porque, diz Coleman, no mínimo, é requerida atenção, um recurso que é sempre escasso.

${ }^{7}$ O termo "fechamento" se refere à ideia de que as redes são fechadas em si mesmas e que as normas as protegem do que é externo.

${ }^{8}$ Há um programa de pesquisa sobre capital espiritual financiado pelo Metanexus Institute que reúne pesquisadores como Peter L. Berger, Laurence R. lannaccone e Roger Finke. Disponível em: <http://www.spiritualcapitalresearchprogram.com>. 
${ }^{9}$ Os adultos são, simultaneamente, membros da igreja e pais de crianças na mesma escola. Isto é, ocorre uma superposição das estruturas ou redes religiosas e educacionais.

${ }^{10}$ Para uma descrição mais detalhada das duas organizações, veja Serafim e Martes (2007). Para saber mais sobre a EdC, veja $<$ http://www.edc-online.org $>$.

${ }^{11}$ Mariápolis Ginetta é uma das várias Mariápolis Permanentes no mundo. Elas são pequenas comunidades onde famílias, jovens, padres e religiosos moram e trabalham, de forma comunitária, constituindo-se também como centros de formação social e religiosa do MF, onde, inclusive, são formados os novos focolarinos(as).

${ }^{12}$ Estevam Hernandes, fundador da igreja, chegou a escrever uma carta convocando os fiéis a não assistirem à Rede Globo. Também os orientou num culto a não lerem a revista Veja.

${ }^{13}$ Não confundir com o individualismo. Tanto na IRC quanto no MF, o indivíduo como princípio e valor está no cerne da doutrina e prática. Aliás, o cristianismo foi a religião que criou e sustentou ao longo do tempo a ideia de que o indivíduo tem valor por si mesmo e não porque faz parte de uma comunidade, raça, etnia, religião ou classe social. A sanção ao egoísmo visa diminuir a probabilidade do indivíduo agir apenas para si e utilizar a organização unicamente para seus próprios interesses. Em outras palavras, o indivíduo é valorizado por si mesmo, mas deve agir visando ao bem da comunidade. Aqui não vale a crença de que vícios privados levam a benefícios públicos.

${ }^{14}$ Tais como: tecnologias religiosas; apoio psicológico; redução dos custos da coleta e acesso à informação, de negociação e do estabelecimento de contratos; informações específicas e interpretadas de acordo com a visão de mundo religiosa; um sistema de significados que cria essa visão de mundo e é sustentado pelas estruturas de plausibilidade, dando-lhes maior grau de certeza, esperança e fé acerca de seus negócios; prestações de serviços técnicos, por parte de membros da organização; desenvolvimento do capital humano, devido à aprendizagem contínua por meio de cursos, seminários, palestras e congressos; trocas de experiência; além da possibilidade de negócios, incluindo possíveis parceiros, fornecedores e clientes. Para um aprofundamento do tema, veja Serafim (2008).

${ }^{15}$ Exprime o sentido do quanto recebemos de alguém, e não do que devemos a ele.

${ }^{16}$ Uma discussão sobre a EdC e o sistema de dádiva está em Leite (2005, p.353).

${ }^{17}$ Para se aprofundar nesse tema, veja Caillé $(2002)$, Godbout $(1998,1999)$ e Mauss $(2003)$. 